Original Research Paper

\title{
Effect of Sorbitol Calcium Chelate on Yield and Calcium Nutrient Absorption of Peanut
}

\author{
${ }^{1}$ Chang Liu, ${ }^{2}$ Yupeng Li, ${ }^{3}$ Wentao Huo, ${ }^{1}$ Tengsheng Li, ${ }^{1}$ Qianqian Wei, \\ ${ }^{1}$ Mingli Huang, ${ }^{4,5 *}$ Cunzhen Geng and ${ }^{1 *}$ Dongyun Yan \\ ${ }^{1}$ College of Environmental Science and Engineering, Qingdao University, Shandong 266071, China \\ ${ }^{2}$ Shandong Lianmeng Chemical Group CO. LTD., Shandong 262700, China \\ ${ }^{3}$ The First Company of China Eighth Engineering Bureau, Shandong 250014, China \\ ${ }^{4}$ State Key Laboratory of Bio-fibers and Eco-textiles, Qingdao University, Qingdao 266071, China \\ ${ }^{5}$ Institute of Marine Biobased Materials, Qingdao University, Qingdao 266071, China
}

\author{
Article history \\ Received: 24-02-2021 \\ Revised: 06-04-2021 \\ Accepted: 08-04-2021 \\ Corresponding Author: \\ Cunzhen Geng and \\ Dongyun Yan \\ College of Environmental \\ Science and Engineering, \\ Qingdao University, Shandong \\ 266071, China \\ Email: qdugcz@qdu.edu.cn \\ yandongyun666@hotmail.com
}

\begin{abstract}
Sorbitol has the effect of promoting nutrient absorption, so it has the potential to produce excellent fertilizers. In this study, sorbitol calcium chelate was synthesized using sorbitol as the chelating agent. The effects of sorbitol calcium chelate on peanut were investigated, with the goal of promoting peanut yield and improving the utilization of calcium fertilizer. Field experiments were carried out in Jimo, Shandong Province, China. Four sorbitol calcium chelate concentrations $\left(0.4,0.8,1.6\right.$ and $\left.2.4 \mathrm{~g} \mathrm{~L}^{-1}\right)$ and two sorbitol non-chelated calcium concentrations (1.6 and $2.4 \mathrm{~g} \mathrm{~L}^{-1}$ ) were tested. Compared with the corresponding sorbitol non-chelated calcium fertilizer treatments, the yield of peanuts increased by 10.0 and $1.7 \%$ under sorbitol chelated calcium concentrations of 1.6 and $2.4 \mathrm{~g} \mathrm{~L}^{-1}$, respectively, besides, the calcium and potassium contents of the seed kernel increased by 32.2 and $55.8 \%$, under sorbitol chelated calcium concentrations of 1.60 and $2.40 \mathrm{~g} \mathrm{~L}^{-1}$, respectively. Sorbitol calcium chelate improved peanut yield and promoted the transformation of sugars to fat in the seed kernel, the $1.6 \mathrm{~g} \mathrm{~L}^{-1}$ concentration produced the best results. Compared with the blank control, the $1.60 \mathrm{~g} \mathrm{~L}^{-1}$ sorbitol chelated calcium fertilizer treatment increased peanut yield by $28.6 \%$, fruit number per plant by $46.8 \%, 100$-kernel weight by $20.4 \%$, full fruit number per plant by $55.3 \%$, fat content by $5.0 \%$. In conclusion, sorbitol chelated calcium fertilizer was superior to sorbitol nonchelated calcium fertilizer under the experimental conditions used herein.
\end{abstract}

Keywords: Sorbitol Chelated Calcium Fertilizer, Sorbitol Non-Chelated Calcium Fertilizer, Peanuts, Yield and Quality, Nutrient Uptake

\section{Introduction}

The self-sufficiency rate of edible oil in China is only $32.2 \%$; thus, China is heavily dependent on imports of edible oil (Gong and Zhou, 2007; Wang, 2011). According to medium and long term national food security plans (2008-2020), the self-sufficiency rate of edible vegetable oil in China should reach at least $40 \%$ by 2020 . The grain and oil yield of peanut per unit area are higher than those of soybean, but measures to promote an increase in peanut yield and fat content are still needed to ensure a sufficient supply of edible oil in China. Calcium is a second messenger in plants that plays an important role in improving the yield and quality of crops, by participating in photosynthesis and cell signaling through the activation of calmodulin (Ryan and Kochian, 1993; Li et al., 2015b; Zhu et al., 2017). The demand for calcium in peanut is higher than that for phosphorus and 2.0-2.5 kg of calcium is absorbed by 100 $\mathrm{kg}$ pods (Zharare et al., 2009; Zhang et al., 2018). Calcium fertilizer is often applied during peanut planting in China by deep application or with water. However, these methods are characterized by a low utilization rate of calcium fertilizer, although this can be overcome by foliar spraying and using these methods in combination is important for improving the yield and quality of peanut.

Applying small molecular compounds, such as sugars and alcohols, during agricultural production has been reported to increase the absorption and utilization of nutrients by crops (Brown and Shelp, 1997; Will et al., 
2011; Zhang et al., 2016). Research has focused mostly on direct spraying or mixing of inorganic salts. Yang et al. (2014; Ding et al., 2015) performed a comparative analysis between sorbitol alcohol and sorbitol calcium fertilizer and which concluded that both promote the absorption of nutrients by crops. However, the chelation reaction between sorbitol and inorganic salt has not been characterized, nor has there been any comparative analysis of the fertilizing effect of sorbitol chelated and sorbitol non-chelated minerals (He et al., 2019; Niu et al., 2020). The mechanism of action of sorbitol alcohol or sorbitol alcohol chelation on crops is controversial. There is no method for detecting chelated fertilizer, which prevents its wide application. In this context, this study used sorbitol-chelated calcium developed by our research group (Yan et al., 2017a-b). The proportions of chelated and non-chelated calcium were determined using detection methods developed in-house (Yan et al., 2018a-b; Bai et al., 2020). Based on field tests of potato, cucumber and strawberry, peanut (Li et al., 2020; Li, 2018; Yang, 2017), which has a high calcium requirement, was investigated in this study. The objective was to systematically analyze the effects of sorbitol-chelated calcium on peanut growth and nutrient uptake under different fertilizer treatment schemes and various chelated calcium spray concentrations. The results should provide a basis for improving the mineral utilization rate of peanut and could help achieve the goal of the Ministry of Agriculture of China of preventing any further increase in fertilizer use after 2020. Finally, the data could serve as a reference promoting the use of chelated calcium in agriculture.

\section{Materials and Methods}

\section{Study Site}

The experiment was carried out at the Peanut test ground in Jimo City, Shandong Province, China from May 4 to September 5, 2018. The basic physical and chemical properties of the $0-20 \mathrm{~cm}$ layer of the test soil were as follows: Soil organic matter content, $8.38 \mathrm{~g} \mathrm{~kg}^{-1}$; alkaline nitrogen content, $89.62 \mathrm{mg} \mathrm{kg}$; ; available phosphorus content, $47.21 \mathrm{mg} \mathrm{kg}^{-1}$; available potassium content, $187 \mathrm{mg} \mathrm{kg}{ }^{-1}$; exchangeable calcium content, $1.96 \mathrm{~g} \mathrm{~kg}^{-1}$; and $\mathrm{pH} 4.98$.

\section{Experimental Materials}

Sorbitol non-chelated calcium (sorbitol + calcium nitrate + calcium acetate) and sorbitol-chelated calcium (produced by the chelation of calcium nitrate and calcium acetate, $\mathrm{Ca}^{2+}>160 \mathrm{~g} \mathrm{~L}^{-1}$, chelation rate $=65.2 \%$ ) were used in the experiments, the chelation rate was determined by the method invented by our research group (Bai et al., 2020; Yan et al., 2018a; 2018b). The peanut variety tested was "Luhua 11".

\section{Experimental Design}

Peanuts were planted on May 4, 2018 and harvested on September 5, 2018. Seven different treatments were applied (Table 1), each of which was repeated three times in $20 \mathrm{~m}^{2}$ plot separated by $1 \mathrm{~m}$. The leaves were sprayed with the treatment agents during the seedling, flowering, podding and fruiting stages. The spraying quantity of calcium was

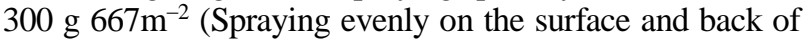
peanut leaves). Nitrogen, phosphorus and potassium were applied as the base fertilizer and the experimental treatments were applied thereafter.

\section{Determination of Indicators and Methods}

\section{Peanut Quality Indicators}

The quality indicators of the peanut seeds were analyzed during the podding, fruiting and mature stages. Crude fat was extracted by the Soxhlet extraction and soluble sugar content was determined by ketone colorimetry.

\section{Determination of Plant Morphology and Yield Components}

Five plants were selected from each plot at harvest time and plant height, lateral branch length and yield were measured.

\section{Determination of the Calcium and Potassium Contents of Peanut}

Whole peanut plants were separated by organ, placed in an oven at $105^{\circ} \mathrm{C}$ for $30 \mathrm{~min}$ and then dried at $80^{\circ} \mathrm{C}$ to a constant weight. The samples were crushed in a stainless steel mill and digested with nitric acid, perchloric acid and hydrofluoric acid. The calcium and potassium contents were determined by Inductively Coupled Plasma Atomic Emission Spectroscopy (ICP-AES).

Table 1: Experimental test setup

\begin{tabular}{lll}
\hline Test treatment & Types of fertilization & Spraying concentration $\left(\mathrm{g} \mathrm{L}^{-1}\right)$ \\
\hline CK & Clean water & - \\
SC0.4 & & 0.4 \\
SC0.8 & Sorbitol chelated calcium & 0.8 \\
SC1.6 & & 1.6 \\
SC2.4 & & 2.4 \\
SN1.6 & Sorbitol non-chelated calcium & 1.6 \\
SN2.4 & & 2.4 \\
\hline
\end{tabular}


Calcium content $\left(\mathrm{mg}\right.$ plant $\left.^{-1}\right)=$ biomass of each organ of the plant $\times$ calcium content of each organ of the plant (Zhao and Fang, 2017).

\section{Statistical Analysis}

The data were analyzed with Excel software (Microsoft Corp. Redmond, WA, USA). Analysis of variance was performed using DPS software (Hangzhou Reifeng Information Technology Ltd. Hangzhou, China). All graphs were drawn with Origin software (Origin Lab Inc. Northampton, MA, USA) and the correlation analysis was conducted with SPSS software (SPSS Inc. Chicago, IL, USA).

\section{Results}

\section{Effects of the Calcium Treatments on Peanut Yield Components}

The exogenous calcium fertilizer increased the number of pods per plant and total yield of peanut, in the order of chelated calcium concentration of $1.60 \mathrm{~g} \mathrm{~L}^{-1}$ $\left(\mathrm{SC}_{1.6}\right)>$ non-chelated calcium concentration of $1.60 \mathrm{~g}$ $\mathrm{L}^{-1}\left(\mathrm{SN}_{1.6}\right)>\mathrm{SC}_{0.8}>\mathrm{SC}_{2.4}>\mathrm{SN}_{2.4}>\mathrm{SC}_{0.4}$. Under a chelated calcium concentration of $1.60 \mathrm{~g} \mathrm{~L}^{-1}$, the yield of peanut increased by $10.0 \%$, the number of fruits per plant increased by $18.6 \%$, the number of full pods per plant increased by $35.6 \%$ and the 100 -kernel weight increased by $10.6 \%$ compared with the values obtained under the non-chelated calcium treatment. Under a chelated calcium concentration of $2.40 \mathrm{~g} \mathrm{~L}^{-1}$, the yield of peanut was $1.7 \%$ higher than that under the non-chelated calcium treatment, the effect of increasing production is no longer apparent, while the 100-kernel weight was increased by $27.4 \%$ and the effect was significant. In turn, the 100-kernel weight under non-chelated calcium was relatively lower than that of the blank control. The yield of peanut first increased and then decreased, as the concentration of chelated calcium was increased. The yield increased by $28.6 \%$ compared with the control and reached a maximum under the $\mathrm{SC}_{1.6}$ treatment. When the spraying concentration was increased further, the peanut yield decreased, but the overall increase compared with the control was large, at $14.5 \%$. Table 2 for specific results.

\section{Yield According to Chelated Calcium Concentration}

The yield of peanut first increased and then decreased, as the spraying concentration of chelated calcium increased. The yields of different spraying concentrations by sorbitol chelated calcium were shown in a scatter diagram (Fig. 1). The results show that the chelated calcium concentrations and yields were in accordance with a univariate cubic equation and the fitting degree was $99.8 \%$, which was significant $(p<0.05)$. Based on the fitting equation, chelated calcium concentration of $1.5^{-1} .8 \mathrm{~g} \mathrm{~L}^{-1}$ increased the yield of peanut by about $28 \%$. We can use a more simpler linear relation to describe the result, that is, the $1.6 \mathrm{~g} / \mathrm{L}$ of the spray concentration of sorbitol chelated calcium is the turning point, the output on the left increases with the increase of spray concentration and the yield on the right is opposite. Therefore, the appropriate spraying concentration of calcium sorbitol chelate is very important to increase the yield.

\section{Effects of Calcium Treatments on Peanut Plant Morphology}

As shown in Fig. 2, the calcium fertilizer promoted the growth of the main stems of the peanut plants compared with the blank control. The $\mathrm{SC}_{0.4}, \mathrm{SC}_{1.6}$ and $\mathrm{SN}_{2.4}$ treatments increased plant height significantly compared with the blank control; for the $\mathrm{SC}_{0.4}$ treatment, the increase was $12.8 \%$. The low and medium concentration chelated calcium treatments led to longer lateral branches than the non-chelated calcium treatments. The $\mathrm{SC}_{1.6}$ treatment yielded lateral branches that were on average $47.66 \mathrm{~cm}$ longer $(5.9 \%)$ than that of the blank control. The average length of the lateral branches was shorter under the $\mathrm{SC}_{2.4}$ fertilizer treatment compared with the blank control. Lateral branch length was shorter under the non-chelated calcium treatments compared with the blank control. On the whole, the chelated calcium treatments were better than the nonchelated calcium treatments on peanut plant morphology.

Table 2: Effects of different fertilizer treatments on peanut yield

\begin{tabular}{|c|c|c|c|c|c|c|}
\hline Treatments & $\begin{array}{l}\text { Number of fruit per } \\
\text { plant (individual) }\end{array}$ & $\begin{array}{l}\text { Number per } \\
\text { plant (individual) }\end{array}$ & $\begin{array}{l}\text { Fruit coverage } \\
\text { rate }(\%)\end{array}$ & $\begin{array}{l}\text { Weight per } 100 \\
\text { kernels (g) }\end{array}$ & Yield $\left(\mathrm{kg} \mathrm{hm}^{-2}\right)$ & $\begin{array}{l}\text { Yield increase } \\
\text { rate }(\%)\end{array}$ \\
\hline$\overline{C K}$ & $12.60 \pm 2.23 \mathrm{a}$ & $7.60 \pm 0.95 c$ & 60.31 & $90.00 \pm 2.84 b c$ & $3521.25 \pm 95.58 \mathrm{~b}$ & 0.00 \\
\hline SC0.4 & $14.00 \pm 1.95 \mathrm{a}$ & $7.66 \pm 0.87 \mathrm{c}$ & 54.71 & $99.60 \pm 3.59 \mathrm{abc}$ & $3725.10 \pm 161.07 \mathrm{ab}$ & 5.77 \\
\hline SC0.8 & $18.00 \pm 2.14 \mathrm{a}$ & $10.00 \pm 1.21 \mathrm{abc}$ & 55.56 & $98.70 \pm 2.61 \mathrm{abc}$ & $4084.65 \pm 103.84 \mathrm{ab}$ & 15.99 \\
\hline SC1.6 & $18.50 \pm 2.69 a$ & $11.80 \pm 0.68 \mathrm{a}$ & 63.78 & $108.40 \pm 4.75 \mathrm{a}$ & $4527.30 \pm 133.34 \mathrm{ab}$ & 28.58 \\
\hline $\mathrm{SC} 2.4$ & $13.10 \pm 1.78 \mathrm{a}$ & $8.00 \pm 0.74 \mathrm{c}$ & 61.06 & $103.80 \pm 4.28 \mathrm{ab}$ & $4031.40 \pm 101.48 \mathrm{ab}$ & 14.47 \\
\hline SN1.6 & $15.60 \pm 1.05 \mathrm{a}$ & $8.70 \pm 0.75 b c$ & 55.76 & $98.00 \pm 2.16 \mathrm{abc}$ & $4114.05 \pm 146.32 \mathrm{ab}$ & 16.84 \\
\hline SN2.4 & $17.30 \pm 1.07 \mathrm{a}$ & $11.00 \pm 1.16 \mathrm{ab}$ & 63.58 & $88.10 \pm 2.91 b c$ & $3965.40 \pm 142.78 \mathrm{ab}$ & 12.62 \\
\hline
\end{tabular}




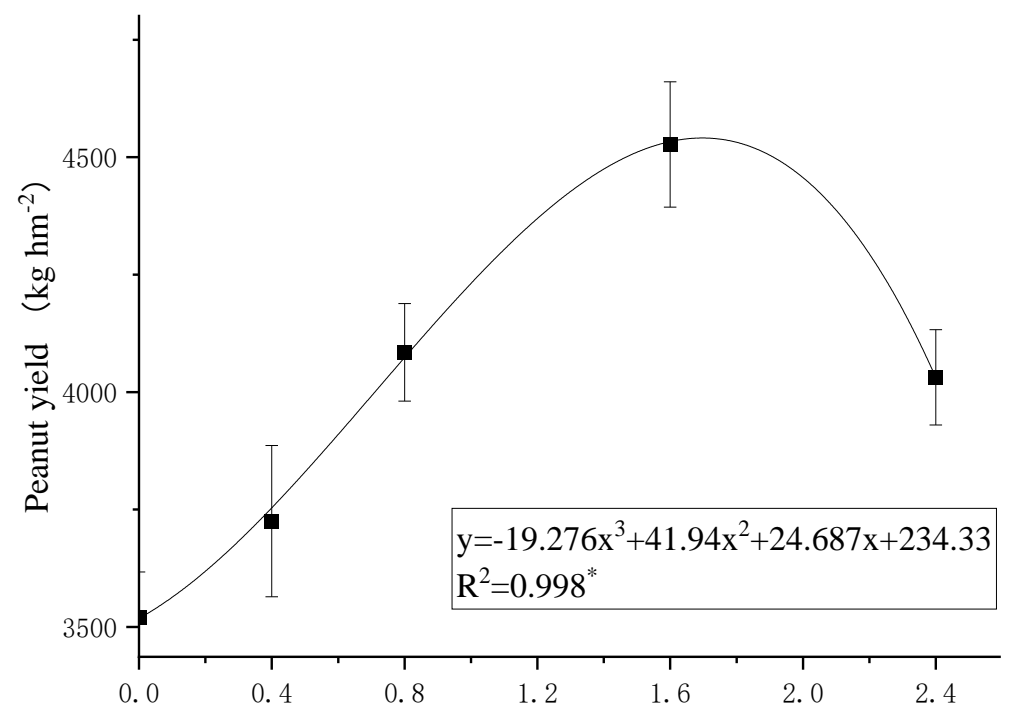

Spray concentration of calcium fertilizer $\left(\mathrm{g} \mathrm{L}^{-1}\right)$

Fig. 1: Effects of different concentrations of chelated calcium fertilizer treatments on peanut yield

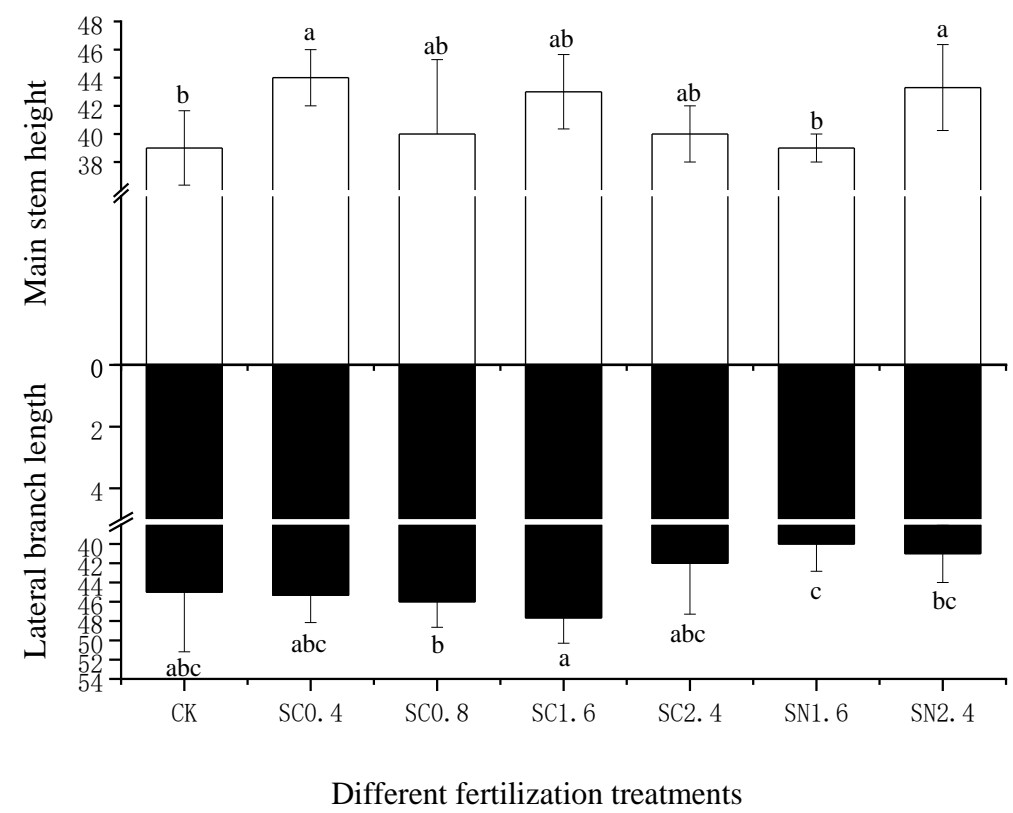

Fig. 2: Effects of different fertilizer treatments on agronomic traits of peanut

Effects of Calcium Treatments on Quality Indices of Peanut Kernels

As shown in Table 3, the fat content of peanut is an important indicator of peanut quality, which determines oil yield. The dynamic trends of peanut fat content accumulation were basically the same under the treatment conditions in this test, fat content increased rapidly during the fruiting stage, but decreased slightly during the mature stage. Spray application of the calcium fertilizer increased fat content. Compared with the $\mathrm{SN}_{1.6}$ treatment, the fat content under the same concentration of chelated calcium was $1.2 \%$ higher at maturity. With a chelated calcium concentration of $2.40 \mathrm{~g} \mathrm{~L}^{-1}$, the fat content was essentially the same as that under the corresponding non-chelated calcium treatment. Compared with other spraying concentrations, the fat content of peanut kernels treated with $\mathrm{SC}_{1.6}$ was higher than that under all other treatments during the entire growth period; the fat content was $50.65 \%$ during the 
harvesting period, which was $5.0 \%$ higher than that of the blank control. The fat contents under the chelated calcium treatments were in the order $\mathrm{SC}_{1.6}>\mathrm{SC}_{2.4}>\mathrm{SC}_{0.4}$ $>\mathrm{SC}_{0.8}$, which represent increases of 5.0, 3.9, 1.3 and $0.4 \%$, respectively, compared with the blank control.

Photosynthetic products are initially stored in kernels as soluble sugars, which are an important indicator of peanut quality. We found that the soluble-sugar content of peanut decreased at the fruiting stage, increased slowly at the mature stage and reached its maximum at harvest. The sugar content of peanut decreased slightly after applying the chelated calcium fertilizer, but the sugar content was higher under the same concentrations of non-chelated calcium, by 4.6 and $11.8 \%$ under the $1.60 \mathrm{~g} \mathrm{~L}^{-1}$ and $2.40 \mathrm{~g} \mathrm{~L}^{-1}$ concentrations, respectively. After harvest, the sugar content under the $\mathrm{SC}_{0.8}$ treatment was $6.2 \%$, which was $1.7 \%$ lower than that of the blank control. The sugar content under the $\mathrm{SC}_{2.4}$ treatment was significantly lower $(10.4 \%)$ than that of the blank control. The sugar content under the chelated calcium fertilizer treatments was in the order $\mathrm{SC}_{0.8}>\mathrm{SC}_{0.4}>\mathrm{SC}_{1.6}>\mathrm{SC}_{2.4}$; all values were lower than that of the blank control.

Compared with non-chelated calcium, chelated calcium treatments can promote the transfer of sugar to fat and the effect of spraying concentration was also very important.

\section{Effects of Calcium Treatments on the Calcium and Potassium Contents of Different Peanut Plant Organs}

As shown in Fig. 3, the calcium and potassium contents in the organs of mature peanut increased in response to the calcium treatments. The calcium content was in the order of leaves > stems > roots > shells > kernels, which was consistent with the direction of calcium migration (from the top to the bottom of the plant). The calcium content of the organs treated with sorbitol chelated calcium was higher than that of the organs treated with non-chelated calcium and the effect of chelated calcium was most obvious on stems and kernels. The calcium content of stems increased by $52.5 \%$ under the $\mathrm{SC}_{1.6}$ treatment compared with that under the $\mathrm{SN}_{1.6}$ treatment and the calcium contents of shells and kernels increased by 9.9 and $32.4 \%$, respectively. The calcium contents of shells and kernels under the $\mathrm{SC}_{2.4}$ treatment were 5.3 and $22.1 \%$ higher, respectively, than those under the $\mathrm{SN}_{2.4}$ treatment. The calcium content of leaves was highest under the $\mathrm{SC}_{2.4}$ treatment, at $19.04 \mathrm{mg} \mathrm{g}^{-1}$, which was $23.5 \%$ higher than that of the control. The calcium content of stems first increased and then decreased, as the sorbitol chelated calcium concentration of the fertilizer increased. The highest calcium content seen was under the $\mathrm{SC}_{1.6}$ treatment. The calcium content began to decrease as the sorbitol chelated calcium concentration of the fertilizer increased. The calcium content increased significantly in roots when the calcium concentration in the spray fertilizer was high. No significant difference was observed in the calcium contents of shells or kernels between the SC1.6 and the SC2.4 treatments (2.89 and 2.84 and 1.60 and $1.62 \mathrm{mg} \mathrm{g}^{-1}$, respectively), but under all of these conditions the contents were higher versus the blank control, the averages were 33.1 and $56.3 \%$ higher than the blank control.

The potassium content of peanut plant organs was in the range 1-6 $\mathrm{mg} \mathrm{g}^{-1}$. With a spray concentration of 2.40 $\mathrm{g} \mathrm{L}^{-1}$, the potassium content of stems treated with the non-chelated calcium fertilizer was higher than that of stems treated with the chelated calcium fertilizer, while the potassium contents of the leaves, roots, shells and other organs were higher than under the non-chelated treatment. Under the $\mathrm{SC}_{1.6}$ and $\mathrm{SC}_{2.4}$, the potassium contents of peanut shells were higher 24.3 and $55.8 \%$, respectively, than under the corresponding non-chelated calcium treatments, similarly, the potassium contents of peanut kernels were higher 1.8 and $9.7 \%$, respectively, than under the corresponding non-chelated calcium treatments. In the four tests of spraying chelate calcium with a gradient of concentrations, the potassium content of leaves reached a maximum when the plants were treated with $\mathrm{SC}_{0.8}(71.0 \%$ higher than that of the control treatment) and gradually decreased as the spraying concentration continued to increase. The potassium contents of roots and stems were highest under the $\mathrm{SC}_{1.6}$ treatment (90.2 and 58.2\% higher than those of the blank control, respectively) and the effect was significant. The potassium content of shells was lower than those of leaves, stems, roots and other organs and no significant difference in shell potassium content was observed based on the chelated calcium concentration of the fertilizer. However, calcium treatment clearly improved the shell potassium content compared with the control treatment. Among all organs, the potassium content was lowest in kernels. The highest potassium content of kernels was $5.64 \mathrm{mg} \mathrm{g}^{-1}$, under the $1.60 \mathrm{~g} \mathrm{~L}^{-1}$ spray treatment. Neither very high nor very low calcium fertilizer concentrations were conducive to potassium accumulation in kernels.

\section{Effects of the Different Fertilization Treatments on Dry Matter Accumulation in Peanut}

As shown in Fig. 4, under the calcium treatments, dry matter accumulation in peanut roots, stems and leaves tended to initially increase and then decrease, as the peanut grew, under the calcium treatments and the trends in roots and stems were basically the same, reaching a maximum during the podding and fruiting periods and decreasing slightly during the mature period. Application of calcium fertilizer promoted the accumulation of dry matter in roots and stems; under 
the same spraying concentrations, accumulation was higher for chelated versus non-chelated calcium. Compared with SN1.6, the SC1.6 treatment increased the dry weights of roots and stems by 6.7 and $8.1 \%$, respectively, during the mature stage. Of the four sorbitol chelated calcium concentrations, the SC1.6 treatment resulted in the highest accumulation of dry matter during the fruiting and maturing stages, with increases in roots and stems of 42.1 and 48.2 and 45.2 and $16.8 \%$, respectively, compared with the blank control. The accumulation of dry matter in leaves reached a maximum in the podding stage and was slightly lower under the chelated calcium treatment than under the non-chelated calcium treatment. Among the four chelated calcium treatments, SC0.4 had the strongest effect on leaf dry matter accumulation, which was $29.4 \%$ higher than that of the blank control. Dry matter accumulation in shells and kernels increased with progression of the peanut growth cycle. The dry matter accumulation values of peanut shells and kernels under the SC1.6 treatment were 2.8 and $7.3 \%$ higher than those under the SN1.6 treatment and 21.7 and $37.9 \%$ higher than those of the blank control, respectively.

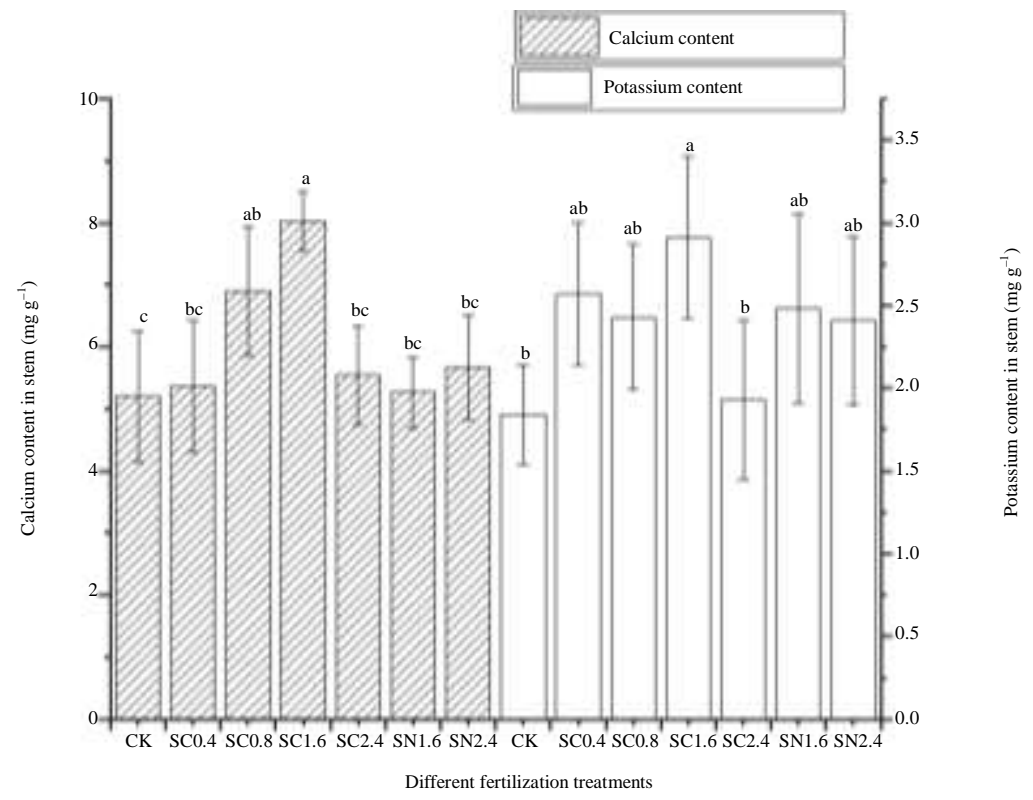

(a)

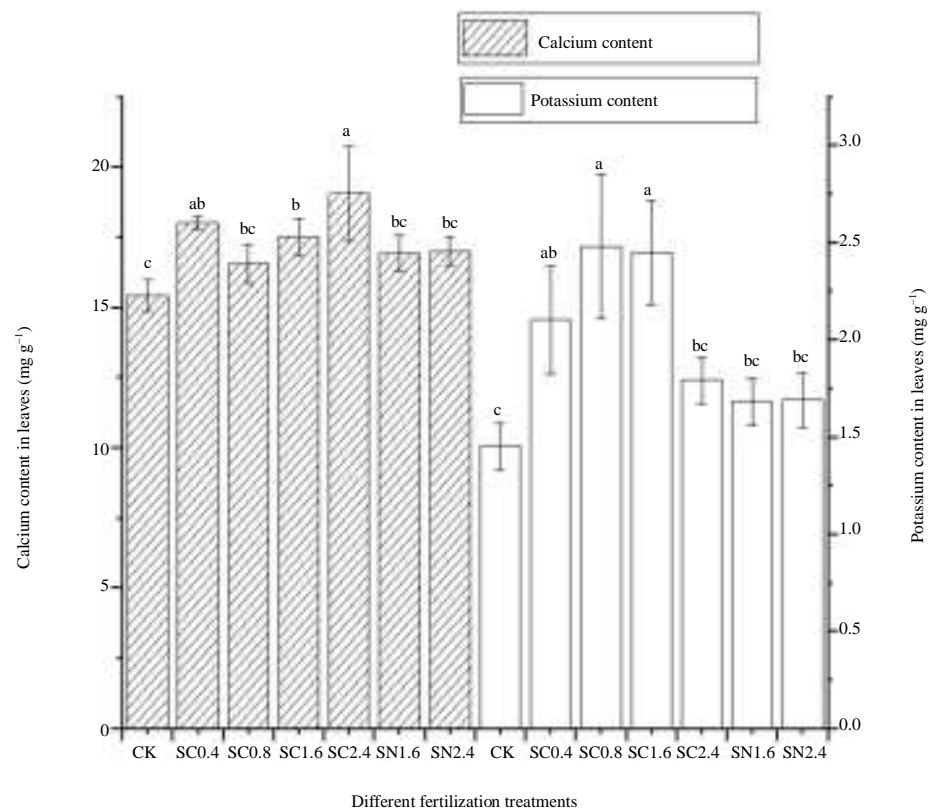

(b) 


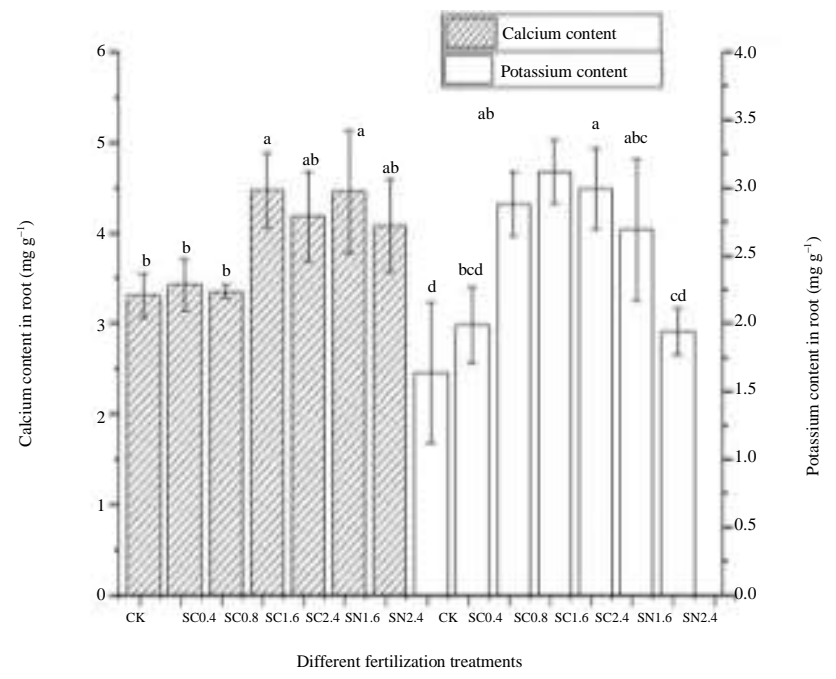

(c)

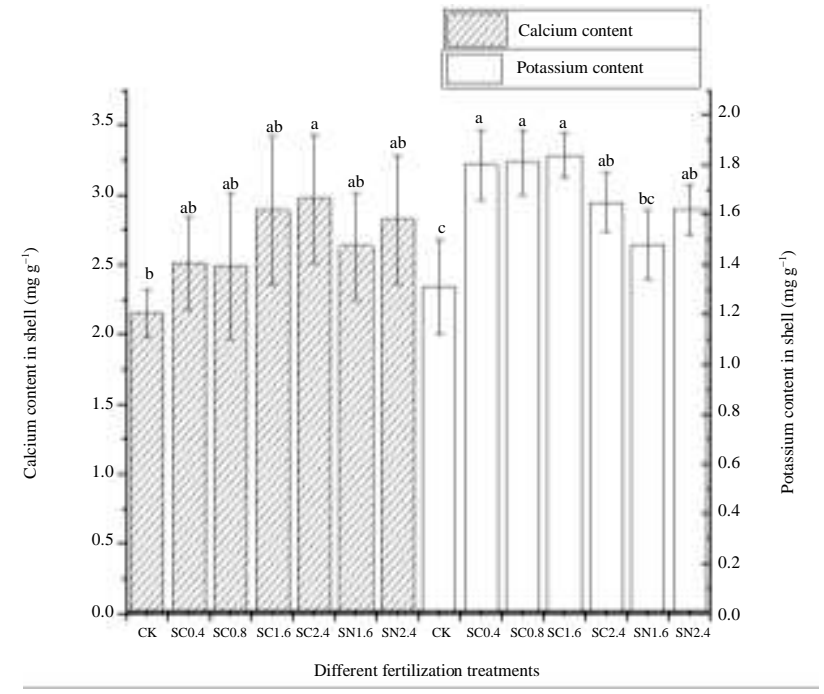

(d)

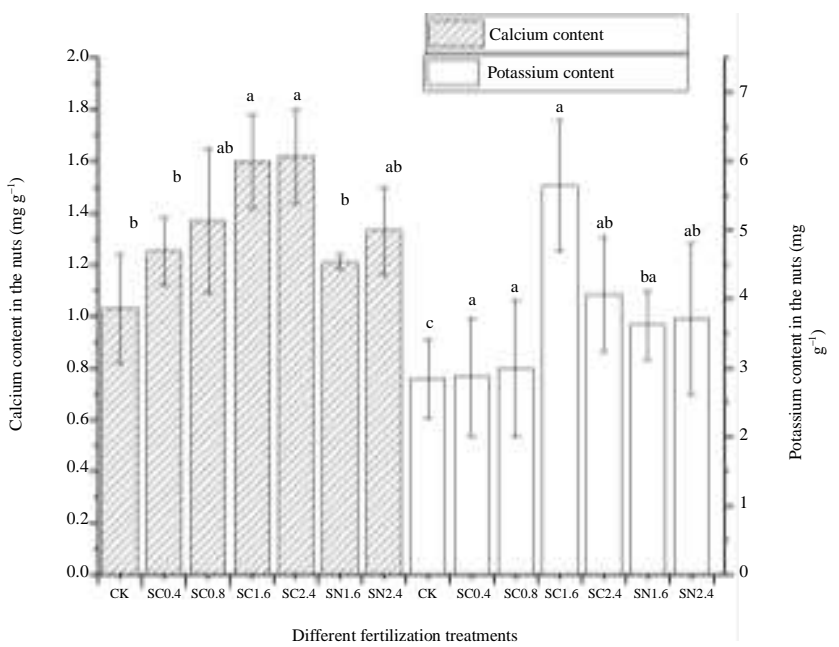

(e)

Fig. 3: Effects of different fertilizer treatments on potassium and calcium contents in peanut organs 


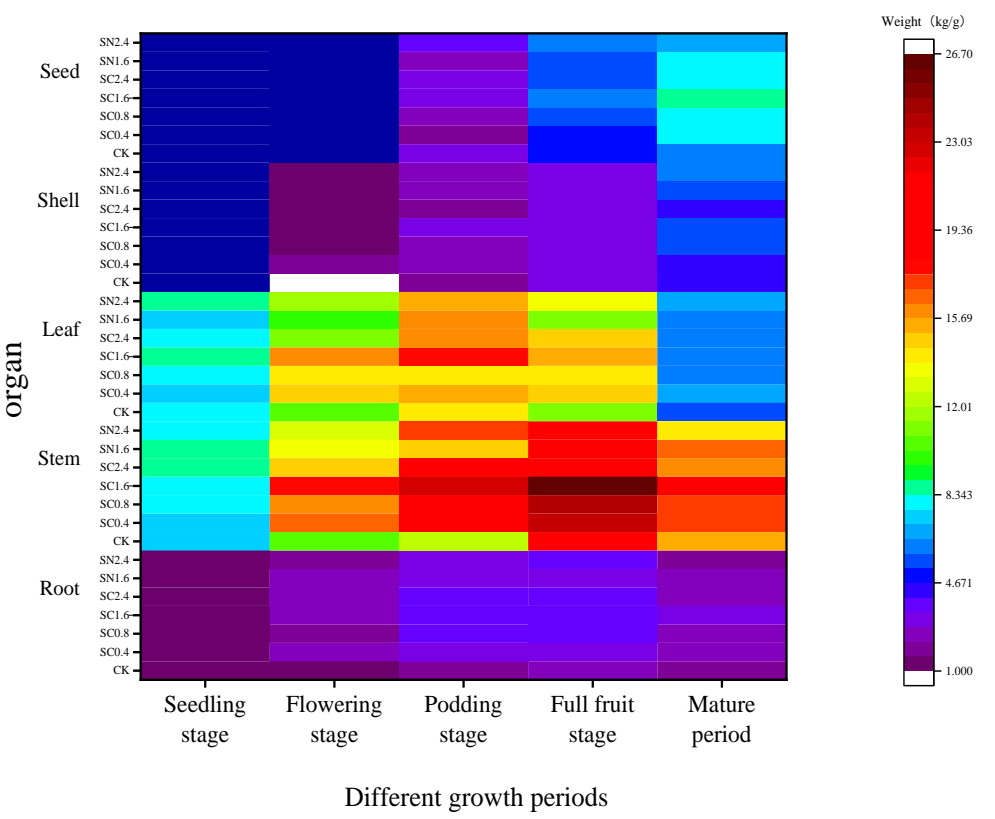

Fig. 4: Effects of the different fertilizer treatments on dry matter accumulation in peanut

\section{Effects of Calcium Treatments on Calcium Accumulation in Peanut Plant Organs}

Calcium fertilizer increased the accumulation of calcium in various organs of the peanut plant. The chelated calcium treatments were more effective in promoting calcium accumulation in all peanut organs compared with the non-chelated calcium treatments, under the same spray concentrations. When the fertilizer calcium concentration was 1.60 or $2.40 \mathrm{~g} \mathrm{~L}^{-1}$, the calcium accumulation values of the roots of chelated calcium-treated plants were 8.8 and $2.2 \%$ higher, respectively, than those of the non-chelated calcium treated plants; the calcium accumulation values of the kernels were 41.7 and 51.3\% higher, respectively and the difference was significant Fig. 5.

The accumulation of calcium in the roots and leaves reached a maximum during the podding stage. In the mature stage, calcium accumulation in the leaves was highest under the SC0.4 and SC2.4 treatments among all fertilizer treatments; the values, of 127.72 and 123.03 $\mathrm{mg}$ plant $^{-1}$, respectively, were 51.3 and $45.7 \%$ higher than those of the blank control. The average amount of calcium in the roots was largest under the SC1.6 treatment, at $12.82 \mathrm{mg} \mathrm{plant}^{-1}(102.5 \%$ higher than the blank control). The accumulation of calcium in the stems reached a maximum during the fruiting stage and the amount of calcium in stems was significantly higher under the SC1.6 treatment compared with the other treatments after the flowering stage; the amount was $80.7 \%$ higher than that of the blank control in the mature stage. The calcium accumulation in shells was similar to that in stems and reached a maximum during the fruiting stage. The accumulation of calcium under the SN2.4 and SC1.6 treatments during the mature stage was higher compared with the other treatments and compared with the blank controls (by 69.4 and 63.5\%, respectively). The accumulation of calcium in kernels increased gradually with growth and was highest under the SC1.6 and SC2.4 treatments (13.62 mg plant ${ }^{-1}$ and $13.48 \mathrm{mg}$ plant $^{-1}$, respectively), being 114.2 and $111.9 \%$ higher than the amounts for the blank control, respectively.

\section{Principal Component Analysis and Correlation Analysis of Peanut Growth and Quality Indicators}

The yield, seed calcium content, seed potassium content, shell calcium content, shell potassium content, fat content, soluble sugar content, number of fruits per plant, 100-kernel weight and dry matter accumulation (X1-X10, respectively) were used as evaluation indices. The SPSS software was used for principal component analysis and the eigenvalues and eigenvectors of each indicator are shown in Table 4. The results show that the first two principal components explained $81.68 \%$ of the variance in the performance indicators.

To determine the relationship between the main principle components and the fertilizer treatments, scores were derived for the different treatments using a formula (Table 5). The scores were higher for all fertilizer treatments than for the blank control, for all performance indicators. The SC1.6 treatment had the highest score, followed by SC0.8; CK treatment clearly had the lowest score, of -3.057 . 


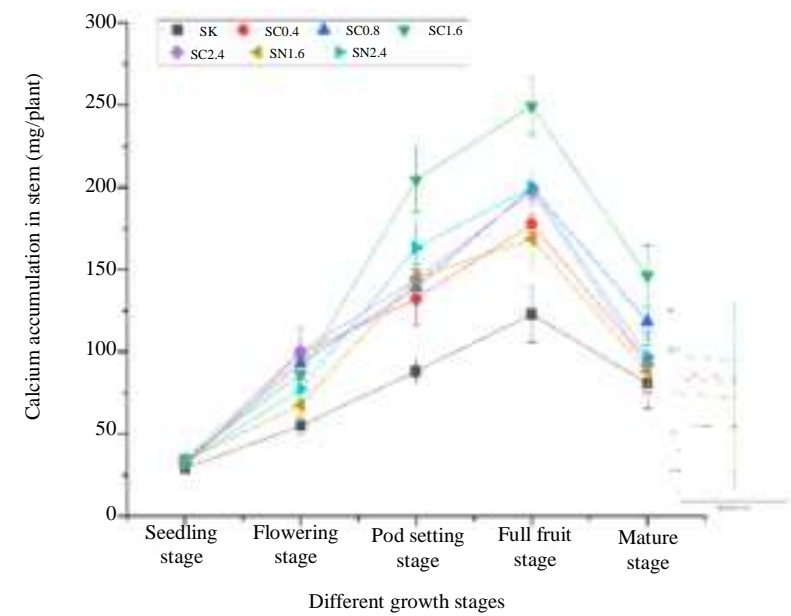

(a)

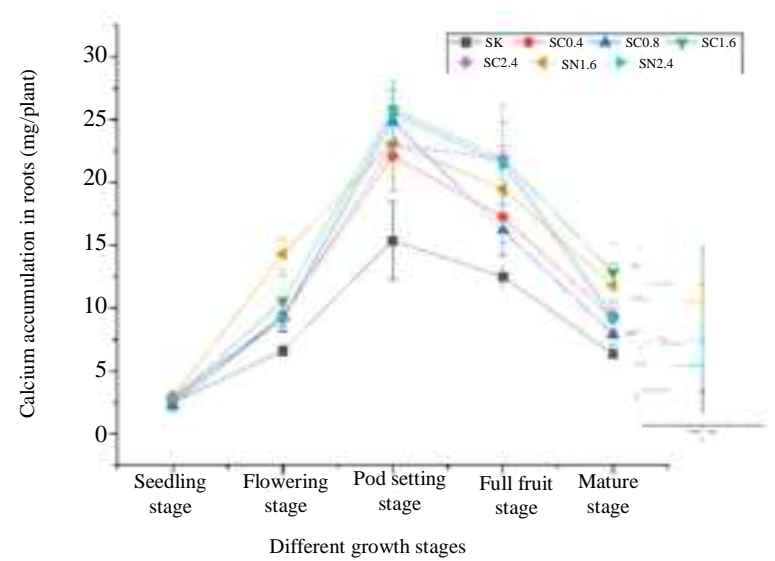

(c)

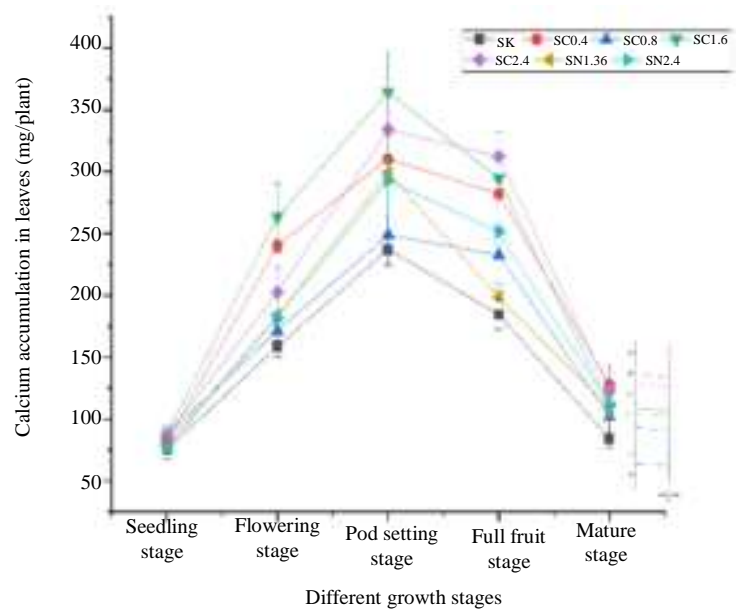

(b)

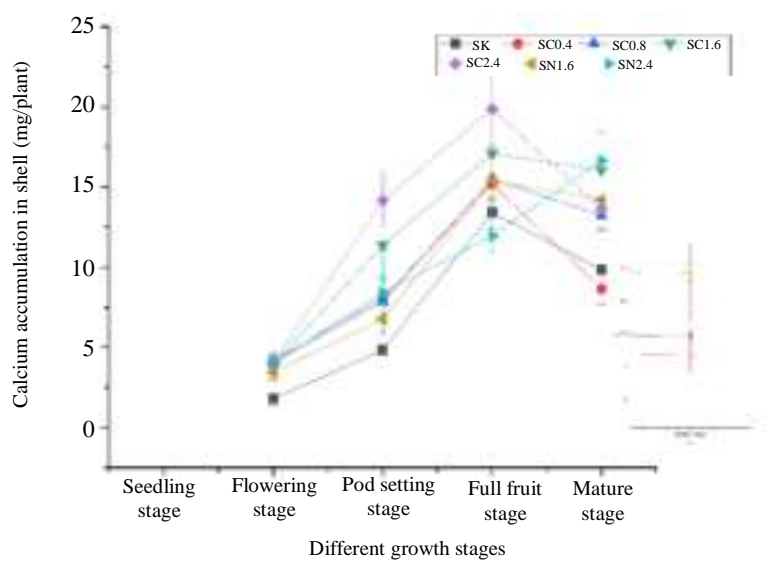

(d)

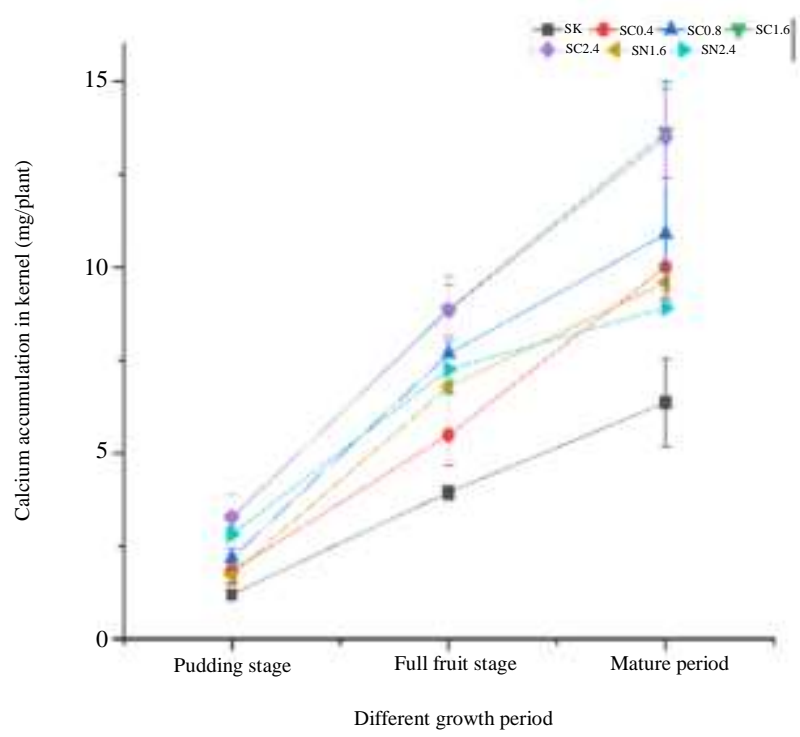

(e)

Fig. 5: Effects of different fertilizer treatments on the calcium accumulation in different parts of peanut 
Table 3: Effects of different fertilizer treatments on peanut quality

\begin{tabular}{lllllll}
\hline Treatments & $\begin{array}{l}\text { Fat content }(\%) \\
\text { Podding stage }\end{array}$ & $\begin{array}{l}\text { Soluble sugar content } \\
(\%) \text { Full fruit period }\end{array}$ & Mature period & Podding stage & Full fruit period & Mature period \\
\hline CK & $42.00 \pm 2.16 \mathrm{~b}$ & $54.85 \pm 1.83 \mathrm{a}$ & $48.26 \pm 0.12 \mathrm{c}$ & $4.12 \pm 0.07 \mathrm{bc}$ & $3.12 \pm 0.03 \mathrm{ab}$ & $6.34 \pm 0.12 \mathrm{a}$ \\
SC0.4 & $42.73 \pm 1.28 \mathrm{~b}$ & $55.85 \pm 1.36 \mathrm{a}$ & $48.88 \pm 0.32 \mathrm{bc}$ & $4.08 \pm 0.42 \mathrm{bc}$ & $3.13 \pm 0.29 \mathrm{ab}$ & $5.76 \pm 0.31 \mathrm{ab}$ \\
SC0.8 & $44.73 \pm 2.16 \mathrm{ab}$ & $55.85 \pm 1.78 \mathrm{a}$ & $48.45 \pm 0.84 \mathrm{c}$ & $4.91 \pm 0.51 \mathrm{a}$ & $2.94 \pm 0.39 \mathrm{ab}$ & $6.23 \pm 0.44 \mathrm{a}$ \\
SC1.6 & $47.10 \pm 0.96 \mathrm{a}$ & $56.36 \pm 0.41 \mathrm{a}$ & $50.65 \pm 0.53 \mathrm{a}$ & $4.25 \pm 0.11 \mathrm{abc}$ & $3.06 \pm 0.04 \mathrm{ab}$ & $5.50 \pm 0.53 \mathrm{ab}$ \\
SC2.4 & $45.14 \pm 1.88 \mathrm{ab}$ & $55.30 \pm 1.25 \mathrm{a}$ & $50.25 \pm 0.32 \mathrm{ab}$ & $3.77 \pm 0.22 \mathrm{c}$ & $2.75 \pm 0.38 \mathrm{~b}$ & $5.08 \pm 0.32 \mathrm{~b}$ \\
SN1.6 & $46.58 \pm 2.16 \mathrm{a}$ & $56.35 \pm 0.74 \mathrm{a}$ & $50.06 \pm 0.36 \mathrm{ab}$ & $4.54 \pm 0.14 \mathrm{ab}$ & $2.71 \pm 0.25 \mathrm{~b}$ & $5.75 \pm 0.34 \mathrm{ab}$ \\
SN2.4 & $44.15 \pm 1.85 \mathrm{ab}$ & $50.45 \pm 1.62 \mathrm{~b}$ & $50.29 \pm 1.19 \mathrm{a}$ & $4.26 \pm 0.13 \mathrm{ab}$ & $3.63 \pm 0.29 \mathrm{a}$ & $5.68 \pm 0.69 \mathrm{ab}$ \\
\hline
\end{tabular}

Table 4: Eigenvalues, contribution proportions and cumulative contribution proportions of the main principle component

\begin{tabular}{llll}
\hline Principle component & Eigen value & Contribution proportion $(\%)$ & Cumulative contribution proportion $(\%)$ \\
\hline F1 & 6.304 & 63.038 & 63.038 \\
F2 & 1.865 & 18.646 & 81.684 \\
\hline
\end{tabular}

Table 5: Comprehensive results obtained under the different peanut treatments

\begin{tabular}{lllrl}
\hline Treatments & F1 & F2 & F & Rank \\
\hline CK & -4.007 & 0.154 & -3.057 & 7 \\
SC0.4 & -1.003 & 0.143 & -0.743 & 6 \\
SC0.8 & 0.092 & 1.934 & 0.512 & 2 \\
SC1.6 & 4.489 & 0.521 & 1.498 & 1 \\
SC2.4 & 0.667 & -2.670 & -0.095 & 5 \\
SN1.6 & 0.117 & 0.017 & 0.094 & 4 \\
SN2.4 & 0.355 & 0.066 & 0.289 & 3 \\
\hline
\end{tabular}

Table 6: Results of the correlation analysis of peanut growth and quality indicators

\begin{tabular}{|c|c|c|c|c|c|c|c|c|}
\hline Factors & Yield (Y) & $\begin{array}{l}\text { Number of fruit } \\
\text { per plant }(\mathrm{N})\end{array}$ & $\begin{array}{l}\text { Weight per100 } \\
\text { Kernels (WK) }\end{array}$ & $\begin{array}{l}\text { Dry matter } \\
\text { accumulation (DW) }\end{array}$ & $\begin{array}{l}\text { Calcium content } \\
\text { Kernels (PK) }\end{array}$ & $\begin{array}{l}\text { Potassium Content } \\
\text { in Kernels (CK) }\end{array}$ & $\begin{array}{l}\text { Calcium Content } \\
\text { in Shell (CS) }\end{array}$ & $\begin{array}{l}\text { Potassium Content } \\
\text { in Shell (PS) }\end{array}$ \\
\hline $\bar{Y}$ & 1 & & & & & & & \\
\hline $\mathrm{N}$ & $0.756 *$ & 1 & & & & & & \\
\hline WK & 0.695 & 0.212 & 1 & & & & & \\
\hline DW & $0.830^{*}$ & 0.604 & $0.829^{*}$ & 1 & & & & \\
\hline $\mathrm{CA}$ & $0.878 * *$ & 0.661 & $0.772 *$ & $0.851^{*}$ & & & & \\
\hline CK & $0.763^{*}$ & 0.387 & 0.748 & 0.612 & 1 & & & \\
\hline PK & $0.854 *$ & 0.485 & 0.645 & 0.576 & 0.751 & 1 & & \\
\hline $\mathrm{CS}$ & 0.726 & 0.371 & 0.521 & 0.520 & $0.878 * *$ & 0.741 & 1 & \\
\hline PS & 0.584 & 0.588 & 0.638 & $0.763 *$ & 0.680 & 0.376 & 0.501 & 1 \\
\hline
\end{tabular}

Some of the performance indicators were included in a correlation analysis. The results are shown in Table 6 . A significant positive correlation was detected between peanut yield and the number of fruits per plant, dry matter accumulation and potassium and calcium contents of kernels; the correlation coefficients were $0.756,0.830$, 0.763 and 0.854 , respectively. The 100-kernel weight was positively correlated with dry matter accumulation; the correlation coefficient was 0.829 .

\section{Discussion}

\section{Effects of Sorbitol Chelated Calcium on Peanut Growth and Yield Components}

Calcium is required for the normal growth and development of plants. Studies have shown that calcium increases the number of peanuts and kernels (and the fullness thereof), thereby increasing the weight of the pods and kernels (Zhou et al., 2008). Calcium and NPK fertilizer are often applied as base fertilizer at one time before or during the sowing of peanut plants. However, this method has a low utilization rate compared with foliar application and often leads to a soil nutrient surplus. This study showed that foliar application of calcium fertilizer significantly increased the number of peanut fruits and the yield. The advantages of foliar fertilizer will gradually become apparent with the intensive agricultural production occurring in China, particularly for field crops. Good photosynthetic characteristics are important for vegetative growth and yield in peanut and the height of the main stems and length of the lateral branches are important indicators of vegetative growth (Xu et al., 2015). The results of this study showed that chelated calcium promoted the absorption of nutrients, crop growth and dry matter accumulation and also improved peanut production compared with non-chelated calcium (inorganic 
calcium). The main reason for these results is that sorbitol, as a preliminary product of photosynthesis, has good chelating properties, including penetration, wetting and reduction of surface tension. Therefore, the sorbitol chelated calcium derived by chelation of sorbitol and inorganic calcium salt promotes the absorption and utilization of nutrients by plants. According to previous results obtained by our research group (Bai, 2018), there is no linear correlation between fertilizer efficiency and the calcium chelation rate and a higher chelation rate is not necessarily better. Biological potency is clearly higher when the chelation rate is $60-70 \%$, so we used chelated calcium produced via a $65.2 \%$ chelation rate as the test fertilizer. The yield increased by $11.7 \%$ compared with the nonchelated calcium treatment when the spray concentration was $1.60 \mathrm{~g} \mathrm{~L}^{-1}$ and increased significantly, by $28.6 \%$, compared with the blank control. However, the increase in peanut yield was greatly reduced when the calcium concentration was increased from 1.60 to $2.40 \mathrm{~g} \mathrm{~L}^{-1}$. It seems that the high-concentration calcium fertilizer inhibited the growth of peanut vegetative organs and reduced peanut yield.

\section{Effects of Sorbitol Chelated Calcium on Peanut Quality, Potassium and Calcium Absorption}

Calcium fertilizer increased the fat content of peanut seeds. During the growth period, the fat content of peanut first increased and then slightly decreased during the mature period. Zhou and others reported that the fat content of peanut tends to show continuous "fast-slow" growth. This phenomenon varies according to the peanut variety (Wang et al., 2003). Fat accumulation slows gradually at maturity and is slower than the rate of dry matter accumulation in pods (Chen et al., 2008). Sugars are the first nutrients to accumulate in kernels. When peanut seeds enter the fruiting stage, the soluble sugar content decreases and then increases on entering the mature stage (Bai and Luo,1964). Applying calcium fertilizer reduces the soluble sugar content of the grain and promotes its conversion into fat (Jiang et al., 2017), which is the basis for calcium fertilizer to enhance the fat content. Under the non-chelated calcium treatment, the soluble-sugar content was higher and the fat content was lower, compared with the chelated calcium treatment. This was because there is a large amount of sorbitol in the non-chelated calcium fertilizer that is not involved in the chelation reaction, the large amount of free sorbitol increases the sugar content of the peanut grain significantly, which in turn inhibits the conversion of sugar into fat in the grain.

The calcium contents of the peanut organs at maturity were in the order leaves > stems > roots > shells > kernels. The calcium fertilizer increased the calcium contents of roots and leaves. Some studies have reported that calcium fertilizer has no obvious effect on the calcium content of shells or kernels (Wang, 2013; Zhao and Fang, 2017). In the present study, the calcium contents of shells and kernels increased significantly under the calcium fertilizer treatments and particularly under the sorbitol chelated calcium treatments; this shows that chelated calcium is effectively transported from vegetative organs to pods at a greater rate compared with ordinary inorganic calcium salt. The relationship between potassium and calcium is complex; on the one hand, these elements compete for adsorption (Lu, 1998), while on the other hand, calcium maintains the integrity of the cell membrane, cell wall and other organs (Huang et al., 2005), thus promoting the absorption of potassium by crops. Zhou et al. (1995) applied calcium nitrate to peanuts and found that it inhibited the absorption of potassium. Other studies have shown that calcium promotes the absorption of potassium by peanuts ( $\mathrm{Yu}$ et al., 2009; Wang et al., 2018). The results of this study show that the potassium content of different organs of peanut under various calcium treatments increased to varying degrees; the potassium content of leaves was highest under the $\mathrm{SC}_{0.8}$ treatment and those of roots, stems, shells and grains were highest under the $\mathrm{SC}_{1.6}$, treatment, but high concentrations of calcium in fertilizer decreased the potassium content significantly. Therefore, the interaction between potassium and calcium was affected by the calcium content of the fertilizer; potassium absorption was promoted by the low-and mediumconcentration calcium treatments, but decreased under the high-concentration treatment. The potassium contents of various peanut plant organs under the high-concentration spray treatment showed that sorbitol chelated calcium alleviated the potassium absorption inhibition of potassium absorption more than did non-chelated calcium chelated calcium is more conducive to the absorption and utilization of nutrients by crops compared with free sorbitol and calcium nitrate and the chelated calcium increased the ability of peanut to cope with external stress compared with the non-chelated calcium.

\section{Effects of Different Concentrations of Sorbitol Chelated Calcium Fertilizer on Nutrient Absorption by Peanut}

An effective fertilizer operation coordinates the accumulation of the crop, keeps the source unblocked and promotes rapid transfer of nutrients to the grain, thus increasing crop yield. Accumulation of dry matter is essential for increasing crop yield (Li et al., 2015a) and appropriate spray concentration is the premise of high quality and high yield. The application of calcium fertilizer on the basis of nitrogen, phosphorus and potassium fertilizer can increase dry matter accumulation in various organs of the peanut plants. Wang et al. 
(2018; Dang et al., 2018) reported that calcium fertilizer improves the quality of peanut vegetative organs and dry matter accumulation in the reproductive organs. Similar results were obtained in this study, the calcium fertilizer treatments increased dry matter accumulation in peanut organs. However, excessive fertilizer decreased the economic coefficient and reduced the accumulation of dry matter to a certain extent, which is not conducive to the accumulation of photosynthetic products in the pods and reduces the effect of increased production (Yang et al., 2014). Under the conditions in this study, the dry matter accumulation in each organ was highest under the $\mathrm{SC}_{1.6}$ treatment; the high-concentration treatment decreased the accumulation. The accumulation of calcium is related to that of dry matter and to the calcium content of the crop, which reflects the calcium fertilizer utilization efficiency. Therefore, it is of important theoretical and practical significance to improve the accumulation of elements and the utilization efficiency of fertilizer by reducing the amount of fertilizer applied to ensure stable crop yields. (Zhang et al., 2016). The results of this study showed that the amounts of calcium in roots, stems, shells and fruits made no difference between the $\mathrm{SC}_{2.4}$ and $\mathrm{SC}_{1.6}$ treatments, indicating that the calcium fertilizer was not used efficiently under the highconcentration treatment. However, the optimum calcium amount might differ among soil fertility conditions. The dry matter accumulation of a crop determines its yield. Fageria et al. (2006; Wang et al., 2017) reported that fertilizer improved the photosynthesis, dry matter quality and nutrient accumulation of peanut. Under the conditions used in this study, the correlation analysis showed that the pod yield was the best indicator of dry matter accumulation and the calcium content in kernels, calcium fertilizer enhances the transport of substances to the seeds, increasing the number of peanut results and dry matter accumulation, increasing peanut yield and the calcium content of the kernels.

\section{Conclusion}

The influence of different concentrations of sorbitol chelated calcium and non-chelated calcium on peanut yield, quality and nutrient absorption was discussed in this study. The results showed that calcium application improved peanut yield, quality, dry matter accumulation and calcium content, meanwhile, sorbitol chelated calcium treatments were better than non-chelated treatments. In addition, the suitable spraying concentration was very important to improve the yield and quality for peanut. The $1.60 \mathrm{~g} \mathrm{~L}^{-1}$ sorbitol chelated calcium fertilizer treatment produced the best results among all seven treatments. Compared with the blank control, the $1.60 \mathrm{~g} \mathrm{~L}^{-1}$ sorbitol chelated calcium fertilizer treatment increased peanut yield by $28.6 \%$, fruit number per plant by $46.8 \%$, 100-kernel weight by $20.4 \%$, full fruit number per plant by $55.3 \%$, fat content by $5.0 \%$, potassium and calcium content in peanut kernel by 98.6 and $55.3 \%$, dry matter accumulation by $37.9 \%$, potassium and calcium content in peanut shell by 34.4 and $40.5 \%$, dry matter accumulation by $21.7 \%$ and calcium accumulation in kernel and shell by $7.26 \mathrm{mg}$ plant $^{-1}$ and $6.24 \mathrm{mg} \mathrm{plant}^{-1}$, respectively. The results of fitting analysis showed that spraying calcium glycolate in the concentration range of $1.5-1.8 \mathrm{~g} \mathrm{~L}^{-1}$ increased the yield of peanut by about $28.0 \%$.

Therefore, as a new high-end fertilizer, sorbitol chelated calcium has a broad prospect of development. The research results of this study provide a technical basis for the popularization and application of sorbitol chelated calcium, which is of great significance to improve the utilization rate of fertilizer and promote the high yield of peanut.

\section{Acknowledgement}

This work was supported by National Natural Science Foundation of China [grant number 31972516] and the Major Research Project of Shandong Province [Public Welfare Special, grant number 2017GNC11116].

\section{Author's Contributions}

Chang Liu and Yupeng Li: Designed and performed the experiments, contributed to the writing of the manuscript.

Wentao Huo, Tengsheng $\mathrm{Li}$ and Qianqian Wei: Participated to collect the materials related to the experiment.

Mingli Huang, Cunzhen Geng and Dongyun Yan: Revised and approved the final manuscript.

\section{Ethics}

The authors declare their responsibility for any ethical issues that may arise after the publication of this manuscript.

\section{Conflict of Interest}

The authors declare that they have no competing interests. The corresponding author affirms that all of the authors have read and approved the manuscript.

\section{References}

Bai, L., Sun, W., Huang, M., Li, L., Geng, C., Liu, K., \& Yan, D. (2020). Study on the Methods of Separation and Detection of Chelates. Critical Reviews in Analytical Chemistry, 50(1), 7889.https://www.tandfonline.com/doi/abs/10.1080/10 408347.2019.1573657 
Bai, L.Y. (2018). Determination of chelate of sugar alcohol and its application. Qingdao University.

Bai, X. W., \& Luo, Y. N. (1964). Development and formation of peanut pods and changes of carbohydrate fat accumulation. Shandong Agricultural Science, 4.

Brown, P. H., \& Shelp, B. J. (1997). Boron mobility in plants. Plant and Soil, 193(1), 85-101. https://link.springer.com/article/10.1023/A:1004211 925160

Chen, S., Li, Y., Xu, G., \& Cheng, Z. (2008). Simulation on oil accumulation characteristics in different highoil peanut varieties. Acta Agronomica Sinica, 34(1), 142. https://en.cnki.com.cn/Article_en/CJFDTotalXBZW200801025.htm

Dang, X. S., Jiang, C. J., Li, J. L., Zhao, K. N., Qu, S. N., Li, N., Wang, J., \& Wang, X. G. (2018). Effects of calcium fertilizer on Peanut Yield and physiological characteristics. Journal of Shenyang Aricultural University, 49(06), 83-89.

Ding, S. S., Li, Y. T., Yuan, L., Zhao, B. Q., Lin, Z. A., Li, J., ... \& Zhang, J. J. (2015). Effects of small molecular organics chelated calcium fertilizer on cherry tomato yield, quality and nutrients absorption. Soil Fertiliz. Sci. China, 15, 61-66. https://kns.cnki.net/kns8/defaultresult/index

Fageria, N. K., Baligar, V. C., \& Clark, R. (2006). Physiology of crop production. CRC Press.

Gong, X. Z., \& Zhou, C. Q. (2007). Vitalizing peanut industry and increasing the self-sufficiency rate of edible oil in China. China Oils and Fats, 1, 9-12.

He, J. L., Huang, M. L., \& Yan, D. Y. (2019). Stability, Structural Characterization and Bio-utilization of Chelated Fertilizers. Spectroscopy and Spectral Analysis, 39(9): 2966-2973. https://schlr.cnki.net/en/Detail/index/SJPD_04/SJPD 00EA71293950D6DDBCF3D6E1B9A1E971

Huang, X. M., Huang, H. B., \& Wang, H. C. (2005). Cell walls of loosening skin in post-veraison grape berries lose structural polysaccharides and calcium while accumulate structural proteins. Scientia Horticulturae, 104(3), 249-263. https://www.sciencedirect.com/science/article/abs /pii/S0304423804002122

Jiang, C. J., Wang, N., Wang, X. G., Wu, D., Zhao, K. N., Dang, X. S., \& Qu, S. N. (2017). Effects of Calcium, Molybdenum and Boron Fertilizer on Peanut Growth, Yield and Quality. Chinese Journal of Oil Crop Sciences, $\quad 39 \quad$ (4), 524-531. https://doi.org/10.7505/j.issn.1007-9084.2017.04.014

Li, D. S., Wen, M. X., Cai, J. H., Qu, Z. X., \& Chen, A. D. (2015a). Regulatory effects of sowing date and dense nitrogen combination on dry matter accumulation and yield of Zhenmai 10. Journal of Triticeae Crops, 35 (10), 1426-1432. https://doi.org/10.7606/j.issn.1009-1041.2015.10.15
Li, W. X., Zhang, X., Shi, Y., \& Lv, W. H. (2015b). Effect of exogenous calcium on potato morphological characters, physiological index, yield and quality traits. Journal of Northeast Agricultural University, 46,4 1-8. https://doi.org/10.19720/j.cnki.issn.10059369.2015.07.001.

Li, F. (2018). Effects of calcium glycolate chelate on potato yield, quality and calcium migration and utilization. Qingdao University.

Li, P. C., Geng, C. Z., Li, L. Y., Li, Y. P., Li, T. S., Wei, Q. Q., \& Yan, D. Y. (2020). Calcium-sorbitol Chelating Technology and Application in Potatoes. American Journal of Biochemistry and Biotechnology, 16(1): 96-102. https://doi.org/10.3844/ajbbsp.2020.96.102

Lu, R. K. (1998). Principles of Soil-Plant Nutrition and Fertilization. Beijing: Chemical and Chemical Industry Press.

Niu, J. H., Liu, C., Huang, M. L., Liu, K. Z., Yan, D. Y. (2020). Effects of foliar fertilization: A review of current status and future perspectives. Journal of Soil Science and Plant Nutrition, 21(1), 104-118. https://doi.org/10.1007/s42729-020-00346-3

Ryan, P. R., \& Kochian, L. V. (1993). Interaction between aluminum toxicity and calcium uptake at the root apex in near-isogenic lines of wheat (Triticum aestivum L.) differing in aluminum tolerance. Plant Physiology, 102(3), 975-982. http://www.plantphysiol.org/content/102/3/975.short

Wang, J. G., Zhang, H., Li, L., Liu, D.W., Wan, S. B., Wang, F., Lu, S., \& Guo, F. (2018). Effects of calcium application and film mulching on uptake and utilization of nitrogen, phosphorus and potassium by peanuts in calcium-deficient red soil. Chinese Journal of Oil Crop Sciences, 40; (1), 110-118. https://kns.cnki.net/kns8/defaultresult/index

Wang, R. Y. (2011). Vigorously develop rape industry and improve the self-sufficiency rate of edible oil in China. Farm Machinery, 14, 8-11. https://kns.cnki.net/kns8/defaultresult/index

Wang, S. J., Xia, G. M., Li, Y. F., Wang, W. Z., \& Chi, D. C. (2017). Effects of biocharcoal-based fertilizer and water stress on peanut physiology and yield. Chinese Journal of Oil Crop Science, 39(6), 827-833. https://doi.org/10.13870/j.cnki.stbcxb.2017.06.044

Wang, X. C., Ma, X. M., Chang, S. M., \& Tang, F. S. (2003). Dynamic studies on pod development and organic matter accumulation of different peanut varieties. Chinese Journal of Oil Crop Sciences 25; (1), 37-39. 9084.2003.01.010

Wang, Y. Y. (2013). Effects of different dosages and ratios of calcium and sulphur fertilizers on physiological characteristics, yield and quality of peanut. Taian: Shandong Agricultural University. https://doi.org/10.7666/d.Y2303864 
Will, S., Eichert, T., Fernández, V., Möhring, J., Müller, T., \& Römheld, V. (2011). Absorption and mobility of foliar-applied boron in soybean as affected by plant boron status and application as a polyol complex. Plant and Soil, 344(1), 283-293. https://doi.org/10.1007/s11104-011-0746-6.

Xu, X. W., Fan, J. B., Chen, Y., Zhang, Q. H., He, Y. Q., \& Zheng, X. B. (2015). Effect of manure combined with chemical fertilizer application on yield, kernel quality and physiological characteristics of peanut to red soil in subtropical China. Acta Pedologica Sinica, 52(1), 174-182.

Yan, D. Y., Bai, L. Y., \& Sun, W. X. (2018a). Determination of chelation rate of sugar alcohol chelated calcium fertilizer based on conductivity method, China, 201810782610.X.

Yan, D. Y., Sun, W. X., Bai, L. Y. (2018b). Determination of chelation rate of sugar alcohol chelated calcium fertilizer by Spectrophotometry, China, 201810783391.7.

Yan, D. Y., He, J. L., Xu, S. H. (2017a). A liquid chelate plant in Hefei: China, 201810491569.0.

Yan, D. Y., Yang, G., \& Xu, S. H. (2017b). A kind of potato claw Hefei: China, 201710511809.4.

Yang, G. (2017). Effect of self-made sugar alcohol calcium fertilizer on vegetable yield and nutrient absorption. Qingdao University.

Yang, J. S., Li, S. X., Zhang, Z. M., Wu, J. X., \& Fan, H. (2014). Effects of Nitrogen Application on Photosynthetic Characteristics and dry matter accumulation of different peanut varieties. Acta Agriculturae Nucleatae Sinica, 28 (1), 154-160.

Yu, J. H., Peng, Z. P., Huang, J. C., Yang, L. X., \&Li,W. Y.(2009). Effects of calcium and Boron Application on nutrient uptake, yield and quality of peanut in paddy soil. Chinese Journal of Tropical Crops | Chin J Trop Crop, 30 (9), 1261-1264.
Zhang, J. L., Guo, F., Sha Yang, S., Geng, Y., Meng, J. J., Wang, L. L., Zhang, S. B., Li, X. G., \& Wan, S. B. (2018). Effects of Different Fertilizer Applications on Calcium Activation, Yield and Quality of Peanut in Acidic Soil. Journal of Soil and Water Conservation, 2, 270-275.

Zhang, L., Shao, Y. H., Gu, S. L., Hu, H., Zhang, W. W., Tian, Z. W., Jiang, D., \& Dai, T. B. (2016). Effects of base fertilizer postshift under reduced nitrogen application on Yield and nitrogen use efficiency of Winter Wheat in South China. Chinese Journal of Applied Ecology, 27(12), 3953-3960.

Zhao, X. F., Fang, Z. G. (2017). Effects of low calcium stress on calcium uptake and distribution characteristics of peanut cultivars. Acta Agriculturae Boreali-Sinica, 32 (2), 194-199.

Zharare, G. E., Blamey, F. P. C., \& Asher, C. J. (2009). Calcium nutrition of peanut grown in solution culture. ii. pod-zone and tissue calcium requirements for fruiting of a virginia and a spanish peanut. Journal of Plant Nutrition, 32(11), 1843-1860. https://doi.org/10.1080/01904160903242359

Zhou, L. Y., Li, X. D., Wang, L. L., Tang, X., \& Lin, Y. J. (2008). Effects of different dosages of calcium fertilizer on physiological characteristics, yield and quality of peanut. Acta Agronomica Sinica | Acta Agron Sin, 34(5), 879-885. https://doi.org/10.3724/SP.J.1006.2008.00879

Zhou, W., Lin, B., \& Zhu, H. Z. (1995). Effects of calcium nitrate on nutrient uptake and soil nutrient status of peanut. Chinese Journal of Soil Science, 6, 279-282.

Zhu, X. Y., Eugénie, R., Lucile, J., Didier, A., Christian, M., \& Jean-Philippe, G. (2017). CML8, an Arabidopsis calmodulin-like protein, plays a role in Pseudomonas syringae plant immunity. Plant and Cell Physiology, 58(2), 307-319. https://doi.org/10.1093/pcp/pcw189. 